prevail among the inhabitants of the Soudan and the White Nile district.

A kind of sign language is occasionally used by the Australians. It consists of figures scratched on "a message stick" made of wood, about four to seven inches long, and one inch wide. Fig. 4 represents one of these sticks. It conveys a message from a black woman named Nowwanjung to her husband Carralinga, of the Woongo tribe. "Other message sticks," says Mr. Lumholtz, "are engraved with straight or circular lines in regular patterns as in embroidery; this has caused an entirely different view of their significance, which supposes them to be merely cards to identify the messenger. This view may be correct, but it is not corroborated by my experience on Herbert River."

Mr. Lumholtz secured a valuable collection of zoological specimens, and some of the best passages in his book are those relating to this part of his work. Fig. 5 represents

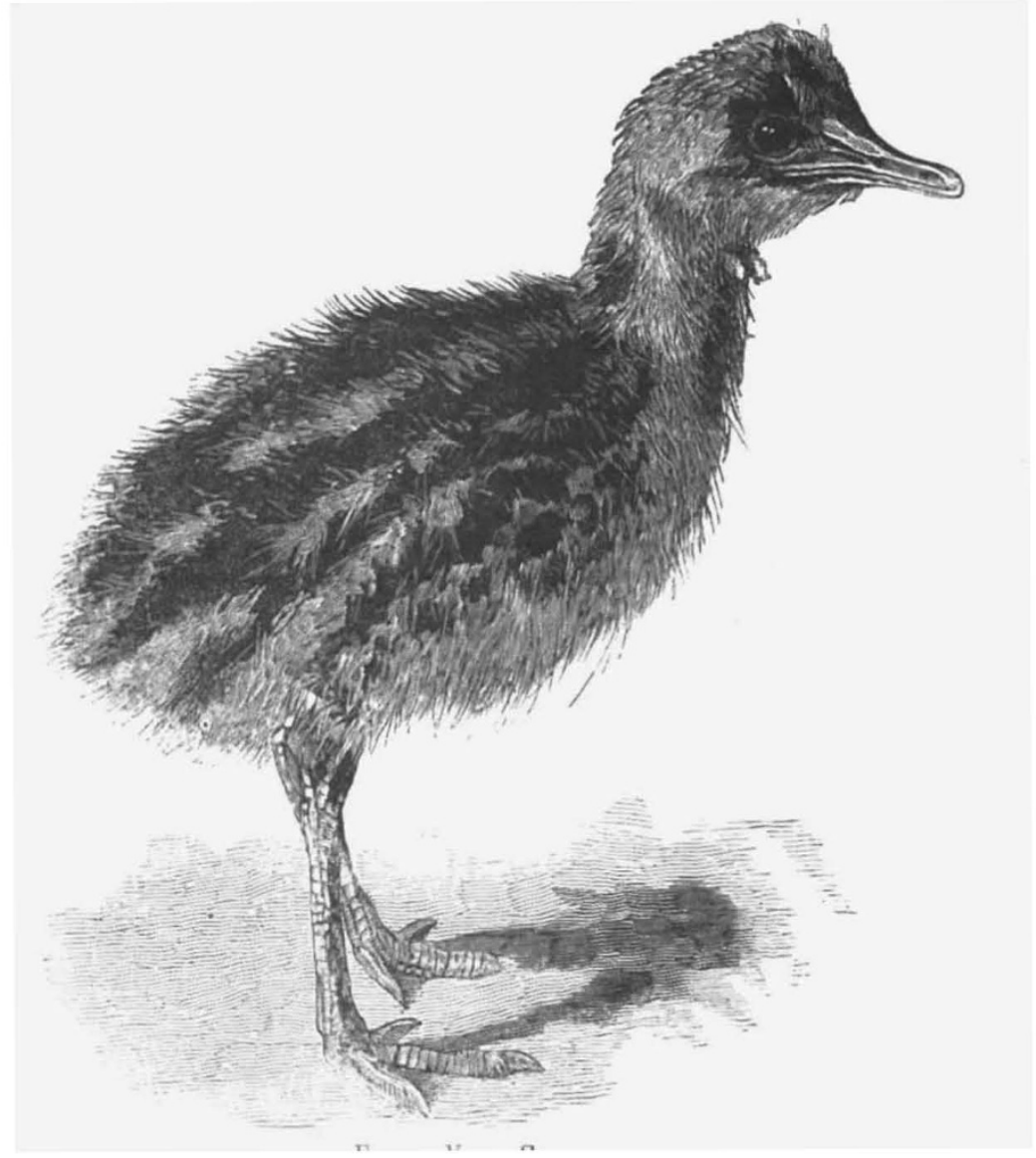

a young cassowary, which the natives one day brought to him, with two eggs. He at once asked the natives to guide him to the nest, near which, in a bed of loose leaves, he placed the young bird, hoping to attract the old one. After the lapse of about ten minutes they suddenly heard the voice of the cassowary. This usually sounds like thunder, "but now, when calling its young, it reminded us of the lowing of a cow to its calf." Soon the beautiful blue and red neck of the bird became visible

\section{BRITISH EARTHQUAKES.}

$\mathrm{I} \mathrm{T}$ is somewhat remarkable that the ordinary notion that Great Britain has a special immunity from serious earthquake phenomena, still very generally obtains credit. An explanation of this popular fallacy may perhaps be found in the simple fact that, on the average, few people living at any one time chance to have experienced any considerable shock; whilst in the case of those few-we except the many who were affected by the disastrous Essex earthquake five years ago-who have felt the sensation, as a momentary mental impression it has been soon for- among the trees. The creature "stopped and scanned its surroundings carefully in the dense scrub, but a charge of No. 3 shot, fired from a distance of fifteen paces, laid it low." Six natives carried home the prize, which proved to be an unusually fine specimen of a male.

We cordially recommend this book to all who take an interest in anthropology and zoology, or in incidents of travel through unfamilar scenes. They will find in it much that cannot fail to give them genuine pleasure.

gotten. It should, however, by this time be more generally known and accepted that no part of the habitable globe is entirely exempt from seismic action, and that earth-tremors of considerable amplitude and intensity are by no means necessarily connected with volcanic disturbances, as was formerly supposed. When it is duly recognized that, at the lowest computation, 600 disconnected shocks are known to have taken place in this country during the present era, the popular belief respecting "our tight little island" may well be entirely shaken. This number includes many earthquakes of considerable magnitude, and the additional seismological 
evidence of modern compilations furnishes the testimony that as many as six or eight minor shocks have occurred annually in recent years. In evidence of the prevalence of such phenomena in England, it should be also remembered that it was on this island that Prof. George Darwin first discovered the fact of the continuous microseismic vibration of the earth's crust.

The new edition of the late Mr. William Roper's excellent summary of the principal earthquakes that have been recorded in Great Britain and Ireland during this era, which has lately been issued, ${ }^{1}$ bears witness both to the frequency of such phenomena, and, even more strikingly, to the great advance that has taken place within recent years in the study of seismology in Britain. The increased attention which has been devoted to the subject is doubtless partly due to the extensive shock which occurred in this country in 1884 .

The famous Catalogue compiled by Robert Mallet will ever remain the cyclopædic work of reference upon which all subsequent earthquake catalogues will necessarily be based; and the name of Mallet, as the authority, naturally figures most extensively in Mr. Roper's list. Until recently, it may, indeed, be said that the work of Mallet, and of M. Alexis Perrey, of Dijon, stood almost alone as the historical register of seismic force in the world. Within the last few years, however, the valuable experimental work of Prof. Milne and others in Japan, and of numerous European and American seismologists, has been supplemented by several treatises devoted to British earthquakes alone. Some of these publications-as the detailed report of the great Essex earthquake, and $\mathrm{Mr}$. E. Parfitt's Devonshire Catalogue-being issued in connection with particular areas, and by local scientific bodies, have had a restricted application; whilst others, as Prof. O'Reilly's catalogue, and the one just mentioned, have included the entire British Islands in their scope. It was the intention of the present writer, when engaged, in conjunction with Prof. Meldola, upon the Report of the East Anglian earthquake, ${ }^{2}$ to furnish a full list of British earthquakes; but, from the quantity of material accumulated from very many sources, it was found that so extensive a catalogue grew entirely out of proportion to the purpose of a special monograph, and only those disturbances which had similarly caused structural damage were included in that memoir. These alone, however, number as many as sixty well-authenticated records, although Mr. Roper, in his catalogue, which, unfortunately, is very scanty in point of detail, omits fully 25 per cent. of these injurious shocks. But since his catalogue too modestly professes to include only "the more remarkable earthquakes," it is to be expected that numerous omissions might be noticed, and we could readily add to his list over two or three dozen records (both mediæval and modern) which fully equalled the average intensity of those he has included. In fact, while it may be said to form the most comprehensive list of British earthquakes that has yet been produced, it is incomplete, and it is much to be regretted that the compiler did not survive to finish his erudite undertaking, as is explained in a prefatory note by his son.

Mr. Roper has, in effect, unconsciously erred unduly on the side of moderation, since he includes most of the fabulous stories that belong to mediæval times, while he has omitted many important shocks. This recalls a somewhat strange incident in connection with the I 884 earthquake-namely, that more damage actually occurred in the out-of-the-way villages chiefly affected by the shock, than was ever reported in the London newspapers--a

I "A List of the more Remarkable Earthquakes in Great Britain and Ireland during the Christian Era." Compiled by William Roper, F.S.S., F.R.Met.Soc. (Lancaster: Thos. Bell.)

2 "Report on the East Anglian Earthquake of April 22, 1884 ." By Raphael Meldola, F.R.S., \&c., and William White. (Essex Field Club Special Memoirs, vol. i.) (London: Macmillan and Co., I885.) fact which does credit to the caution exercised by the daily press writers at the time. Too much, on the other hand, was made of the really slight but widely distributed shock which took place on May 30 in the present year, when no displacement of furniture nor stoppage of clocks then resulted; the experience being limited to the rattling of windows and the swaying of walls, as may be seen on referring to the summary which appeared in NATURE for June 6 (pp. I40-42).

Covering so considerable a period of history, and including so much subject-matter, Mr. Roper's work certainly deserved a more extended treatment than it has received. An introductory analytical chapter would have added considerably to the interest of such a catalogue, while a fuller elaboration and thorough editing would have advantageously extended the work beyond its unpretentious limit of fifty pages. The convenient method adopted by Mr. Roper of inserting a preliminary list of "principal authorities cited," is almost compulsory in such a work, for the purpose of establishing a code of abbreviations for subsequent use in the columns of the list; but the titles are generally given imperfectly or incorrectly, without the requisite details of publication, while the dates, where given, are not throughout those of the original, as they should be, but of later reprints. These and similar slight defects are inconvenient in an historical treatise, and we hope they may receive attention in the event of another edition of this interesting list being called for.

The total number of distinct earthquakes included in this catalogue-regarding the series of repeated shocks which sometimes take place within a brief period as a single record-amounts to 582 , and an analysis of these records may be of interest here, as furnishing some slight indication of the chronological distribution of the chief seismic disturbances which have been accounted in British annals as having taken place within our area. They may, for convenience, be arranged as they occurred during each century, and term of 500 years : thus-

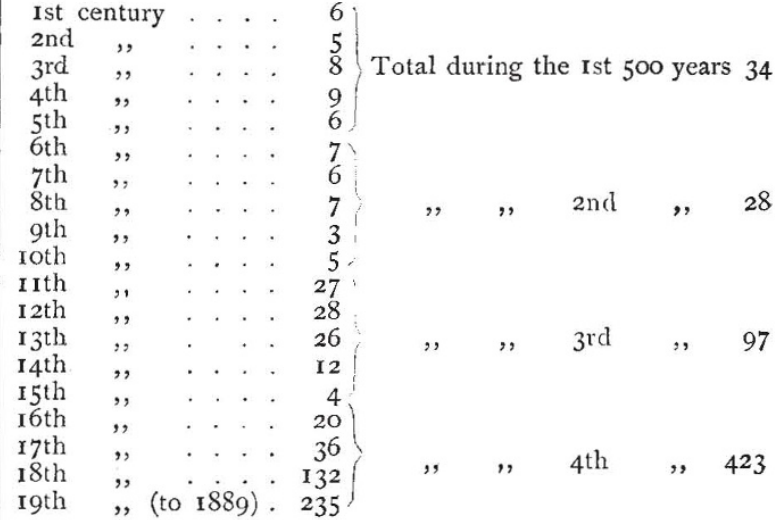

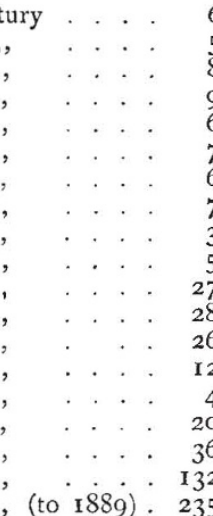
It may perhaps be fairly assumed from this table that no true estimate of the actual number of shocks happening within each period can be arrived at, for the chief reason that the records are entirely subject to the irregularities of the few capable observers of the early centuries. It is to be observed that 423 shocks, or nearly 75 per cent. of the total number, have occurred since I600, which may be considered as the period from which the more trustworthy accounts commenced. There is no reason whatever for supposing that the frequency of seismic shocks has increased since that period; and the evidence indicates little more than the activity of the observers, who appear to have fallen off considerably at times, as during the fourteenth and fifteenth centuries. This point is worth remarking, on account of the misleading statement that has been more than once made, 
that the twelfth century was specially subject to earthquakes.

Since the development of telegraphy, and the consequent rapid production of daily press news, the means of recording such phenomena with prompt accuracy has of course been greatly facilitated. This is very apparent when the number of shocks which have occurred within the present century is apportioned into decades of ten years. Thus-

$$
\begin{aligned}
& \text { In } 1800-10 \text { there were } 9 \text { shocks recorded. } \\
& \text {, } 1811-20 \quad \text { " } 36 \text {, } \\
& \text {,, } 1821-30 \quad,, 23 \text { ", } \\
& \text {, I83I-40, ", } 49 \\
& \text {," } 1841-50 \quad \text { ", } 27 \quad \text { ", } \\
& \text {,, } 1851-60 \text {," } 12 \text {,, } \\
& \text {, 186I-70 , , } 25 \text {, } \\
& \text { ", 1871-80 ", } 18 \text { ", } \\
& \text {, I88I-88, ,, } 34
\end{aligned}
$$

Although it appears from this artificially divided list as if a low decade was followed, as a rule, by a high decade, the number being often doubled, no safe computation whatever can be inferred; and the more one considers the facts accumulated, the more one feels that there is no real evidence upon which the various conjectures respecting earthquake periodicity have been made. About a dozen only of the numerous Comrie shocks are included in the above figures, but even this number is sufficient to materially affect any such calculation, whilst very many other well-authenticated shocks, as already mentioned, are omitted in $\mathrm{Mr}$. Roper's list. With regard to Comrie, in Perthshire, it may further be remarked that, during the month of October I839, as many as sixty-six separate shocks are reported to have taken place; and during the years I 839-42, altogether upwards of 200 vibrations were experienced in that district (vide NATURE, vol, xxiii. pp. II 7 and I70).

With regard to the trustworthiness of the earlier records, it may be generally assumed that some earth vibration did actually take place at the time stated, notwithstanding the exaggerations and extraneous notions that were mixed up with such phenomena in superstitious times. But whether the occurrence was in every case an earthquake in the proper sense of the term is open to doubt. It is, indeed, highly probable that such occurrences as that recorded under the date of June $7,175^{\circ}$, and other more recent cases, were not earthquakes at all, but the effect of bursting bolides, similar to the phenomenon which was described very fully in Symons's Meteorological Magazine for December 1887 . Others, again, appear to have been no more than extensive landslips, or other superficial rock displacements resulting from aërial denudation; while some others were probably only connected with violent storms, or the frost-cannonadings which are commonly produced on exposed chalk cliffs during the winter season.

The absurd statements that were made respecting some of the older occurrences are evidently either intentional or unintentional falsehoods; but many of them contain so much quaint humour that a few samples are well worth quoting. In the year I $3^{2}$ A.D. there was a terrible earthquake in England, when "men and cattle were swallowed up "; but this fashion in recording events had been set at least twenty-nine years earlier, for in the year 103, "a city is said to have been swallowed up." In 418 there was one that was "great and general ; then famine, plague, hail, snow, cold, and meteors." In 505 one lasted for three hours. At about three o'clock on August II, I089, there was a terrible one in England, which caused great scarcity of fruit, and a late harvest; while twelve years later there was another that "terrified all England with a horrid spectacle, for buildings were lifted up and then again settled as before." Again, in I 177 , near Darlington, "the earth swelled up to a great height from nine in the morning to the setting of the sun, and then with a loud noise sank down again "; there was another that took up all the day in IIIO; while on September 11, 1275, a great earthquake was felt in Newcastle, with "dreadful thunder and lightning, blazing stars, and a comet,.... with the appearance of a great dragon, which terrified the people between the first and third hour of the day." This savours somewhat of the Chinese dragon fables, while some others almost match the deluge of Noah in their vast extent. In 974, for instance, "a great one shook the whole of England"; while earlier still, in 856 , one occurred "over the greatest part of the known world." In II33, "in manie parts of England an earthquake was felt so that it was thought that the earth would have sunke under the feete of men, with such a sound as was horrible to heare." In. 1290, there was one felt in England that was described as being " nearly universal (!) in Europe"; while we are assured, with circumstantial evidence, that, in the year 1426, " on the even of St. Michael the Archangel, in the morning before day, betwixt the hours of one and two of the clocke, beganne a terrible earthquake, with lightning and thunder, which continued the space of two houres, and was universal through the world. The unreasonable beasts rored and drewe to the townes with hideous noise ; also the fowls of the ayre likewise cried out."

Space does not permit of other equally curious accounts, as marvellous almost as the more primitive traditions of patriarchal times regarding the vindictive forces of Nature.

Whatever may be said about the accompaniments and absurd effects which have been ascribed to earthquake action, the majority of those shocks which are recorded as having caused damage to buildings may fairly be set down as facts, and although they may have occasionally been exaggerated, some of the details are generally authentically described.

A curious problem may be raised with regard to the effect of earthquakes upon river courses. That shoals have frequently been produced along marine coasts is well known, a striking case being that which happened early in January I 885, off Malta, to the extent of dangerously affecting navigation; but there are several accounts which agree in the assertion that the beds of such navigable streams as the Trent and the Thames have been temporarily raised by local earthquakes so as to permit of people "passing over dry-shod." What became of the river course during the operation is a problem that does not appear to have required solution. Yet sufficient circumstantial evidence has been produced, in connection with the shock in IIIO at Nottingham, and in 1158 at London, to almost warrant the idea that a certain amount of credence may be given to the stories. Whether it may be inferred from such statements that a change in the bed of the rivers in question then took place is doubtful, as history yields us no information on the point.

As a general statement we may safely infer finally that earthquakes in Great Britain, including the microseismic disturbances which are now so frequently recorded, were as common in the past as in the present period of more scientific observation; though, fortunately, such calamitous results as attended the catastrophe in Essex within recent times continue to be rare. It is still a matter for regret, however, that no steps have yet been taken to establish seismographs in different parts of this country. Until this is done, the chance records of various individualswhose impressions, being inevitably affected more or less by the personal equation, produce only doubtful datamust continue to take the place of precise observation.

WILLIAM WHITE. 